Fetal Diagnosis and Therapy
Fetal Diagn Ther 2011;29:127-134

DOI: $\underline{10.1159 / 000322138}$
Received: October 4, 2010

Accepted after revision: October 19, 2010 Published online: December 16, 2010

\title{
Contribution of Ductus Venosus Doppler in First-Trimester Screening for Major Cardiac Defects
}

\author{
Teodora Chelemen ${ }^{\mathrm{a}, \mathrm{c}}$ Argyro Syngelaki $^{\mathrm{a}-\mathrm{c}}$ Nerea Maiz $^{\mathrm{d}}$ Lindsey Allan $^{\mathrm{a}}$ \\ Kypros H. Nicolaides ${ }^{a, b}$ \\ ${ }^{a}$ Harris Birthright Research Centre of Fetal Medicine, King's College Hospital, and bepartment of Fetal Medicine, \\ University College Hospital, London, and ' Department of Fetal Medicine, Medway Maritime Hospital, Chatham, UK; \\ dUnidad Medicina Fetal, Centro Sanitario Virgen del Pilar, San Sebastián, Spain
}

\section{Key Words}

First-trimester screening $\cdot$ Cardiac defects $\cdot$ Nuchal translucency $\cdot$ Ductus venosus Doppler $\cdot$ Ultrasound $\cdot$ Prenatal diagnosis

\begin{abstract}
Objective: To determine whether assessment of ductus venosus flow at 11-13 weeks' gestation improves the detection rate of cardiac defects achieved by screening with nuchal translucency (NT) thickness. Methods: Prospective first-trimester screening for aneuploidies, including measurement of fetal NT and assessment of ductus venosus flow. The performance of different combinations of increased fetal NT and abnormal blood flow in the ductus venosus in screening for major cardiac defects was examined. Results: The study population of euploid fetuses included 85 cases with major cardiac defects and 40,905 with no cardiac defects. The fetal NT was above the 95th and above the 99th centile in 30 (35.3\%) and 18 (21.2\%) of the fetuses with cardiac defects, respectively, and in 1,956 (4.8\%) and $290(0.7 \%)$ of those without cardiac defects, respectively. Reversed a-wave was observed in 24 (28.2\%) of the fetuses with cardiac defects and in 856 (2.1\%) of those with no cardiac defects. Specialist fetal echocardiography for cases with NT above the 99th centile
\end{abstract}

\section{KARGER}

Fax +4161306 1234

E-Mail karger@karger.ch

www.karger.com (c) 2010 S. Karger AG, Basel

1015-3837/11/0292-0127\$38.00/0

Accessible online at:

www.karger.com/fdt and those with reversed a-wave, irrespective of NT, would detect $38.8 \%$ of major cardiac defects at an overall falsepositive rate of $2.7 \%$. Conclusions: Assessment of ductus venosus flow improves the performance of NT screening for cardiac defects.

Copyright $\odot 2010$ S. Karger AG, Basel

\section{Introduction}

Abnormalities of the heart and great arteries are the most common congenital defects and they account for about $20 \%$ of all stillbirths and $30 \%$ of neonatal deaths due to congenital defects [1]. Although most major cardiac defects are amenable to prenatal diagnosis by specialist fetal echocardiography, routine ultrasound screening in pregnancy fails to identify the majority of affected fetuses [2-4]. Consequently, effective population-based prenatal diagnosis necessitates improved methods of identifying the high-risk group for referral to specialists.

The traditional method of screening for cardiac defects, which relies on family history of such defects, maternal history of diabetes mellitus and maternal exposure to teratogens, identifies only about $10 \%$ of affected fetuses [5]. A major improvement in screening for cardiac de- 
fects came with the realization that many affected fetuses have increased nuchal translucency (NT) thickness at 1113 weeks' gestation [6]. In a recent screening study of more than 40,000 singleton pregnancies, excluding aneuploidies, there were 85 fetuses with major cardiac defects and in $30(35.3 \%)$ of these the NT at 11-13 weeks was above the 95th centile [7]. Similarly, in the combined data from 14 first-trimester screening studies on major cardiac abnormalities in euploid fetuses, the fetal NT was increased in 73 (33.0\%) of the 221 cases [7]. Another early sonographic marker of major cardiac defects is abnormal blood flow in the ductus venosus [8]. In the combined data from eight studies that examined ductus venosus waveforms in 791 euploid fetuses with increased NT thickness abnormal Doppler waveforms in the ductus venosus were observed in $87 \%$ of those with cardiac defects compared to $19 \%$ in those without cardiac defects [9]. However, there is uncertainty as to whether abnormal flow in the ductus venosus in fetuses with major cardiac defects is confined to those with increased NT or it is also observed in fetuses with normal NT [10, 11].

In this study, we investigate further the association between fetal major cardiac defects, abnormal flow in the ductus venosus and NT thickness. The aim is to determine whether assessment of ductus venosus flow improves the overall detection rate of cardiac defects achieved by screening with NT thickness alone.

\section{Methods}

\section{Screening Study Population}

The data for this study were derived from prospective firsttrimester screening for aneuploidies at King's College Hospital, London, UK, and Medway Maritime Hospital, Gillingham, UK, between March 2006 and September 2009. In this visit, which is held at $11^{+0}-13^{+6}$ weeks of gestation, maternal characteristics and medical history are recorded and an ultrasound scan is performed transabdominally (using 3-7.5 MHz curvilinear transducers) to, firstly, determine gestational age from the measurement of the fetal crown-rump length (CRL), secondly, measure fetal NT thickness, and, thirdly, diagnose any major fetal abnormalities $[12,13]$. At King's College Hospital assessment of risk for aneuploidies included measurement of maternal serum free $\beta$-hCG and PAPP-A [14]. In both hospitals, ductus venosus blood flow velocity waveforms were also routinely obtained.

In the ductus venosus studies the following criteria were fulfilled [15]: (a) the examinations were undertaken during fetal quiescence, (b) the magnification of the image was such that the fetal thorax and abdomen occupied the whole screen, (c) a right ventral mid-sagittal view of the fetal trunk was obtained and color flow mapping was used to demonstrate the umbilical vein, ductus venosus and fetal heart, (d) the pulsed Doppler sample was small $(0.5-1.0 \mathrm{~mm})$ to avoid contamination from the adjacent veins and it was placed in the yellowish aliasing area which is the portion immediately above the umbilical sinus, (e) the insonation angle was less than $30^{\circ}$, (f) the filter was set at a low frequency (50-70 $\mathrm{Hz}$ ) to allow visualization of the whole waveform, and $(\mathrm{g})$ the sweep speed was high $(2-3 \mathrm{~cm} / \mathrm{s})$ so that the waveforms were widely spread allowing better assessment of the a-wave. Waveforms were assessed qualitatively and considered to be abnormal if the a-wave was reversed.

The policy in our hospitals is to offer routinely a second ultrasound examination at $20^{+0}-23^{+6}$ weeks. This scan is also performed transabdominally and involves systematic detailed examination of the fetus, including a sweep through the heart in transverse plane to include the four-chamber view, outflow tracts and three-vessel view of the heart and great vessels.

During the study period, the first- and second-trimester scans were carried out by 1 of 165 sonographers who had obtained the Fetal Medicine Foundation Certificates of Competence in the 1113 weeks' scan and the 18-24 weeks' scan or by trainees under the supervision of certified sonographers. All cases of suspected fetal abnormalities were examined by a fetal medicine specialist. Likewise, all cases of suspected fetal cardiac defect were examined by a fetal cardiologist. In addition, the cardiologists carried out fetal echocardiography at 11-14 weeks in those with NT above the 99th centile and at 20 weeks in those with NT between the 95th and 99th centiles.

In our hospitals all babies are examined in the neonatal period by a pediatrician. Prenatal and neonatal findings are recorded in computerised databases. Data on pregnancy outcome from women who book for obstetric care in our hospitals but deliver in other hospitals are obtained either from the maternity computerised records in these hospitals or the general medical practitioners of the women.

Inclusion Criteria for This Study and Outcome Measures

In this study, we compared the measurements of fetal NT and ductus venosus blood flow at 11-13 weeks in pregnancies with major fetal cardiac defects and those resulting in live birth of phenotypically normal babies.

Cardiac defects are considered to be major if they require surgery or interventional cardiac catheterization within the first year of life. We included all cases with major cardiac defects diagnosed by pediatric cardiologists either antenatally and/or in the neonatal period. Abnormalities suspected antenatally but not confirmed in the neonates were not included. In contrast, the prenatal diagnosis in cases of terminations and miscarriages at less than 24 weeks or stillbirths at or after 24 weeks were assumed to be correct because in these cases postmortem examination was not performed systematically. The following fetal cardiac defects were not included: firstly, ventricular septal defects because they are generally not considered to be major defects, secondly, right aortic arch, persistent left superior vena cava and aberrant right subclavian artery because these are variants of normal rather than true defects, and thirdly, cardiac tumors developing during the second and third trimesters of pregnancy because these defects would not be expected to have any manifestations during the 11-13 weeks' scan.

We excluded all aneuploidies and non-cardiac defects diagnosed prenatally or in the neonatal period. We also excluded pregnancies with no abnormal fetal findings at the 11-13 weeks' scan and/or the 20-23 weeks' scan which resulted in termination, miscarriage or stillbirth and those lost to follow-up. 
Fig. 1. Description of the study population.

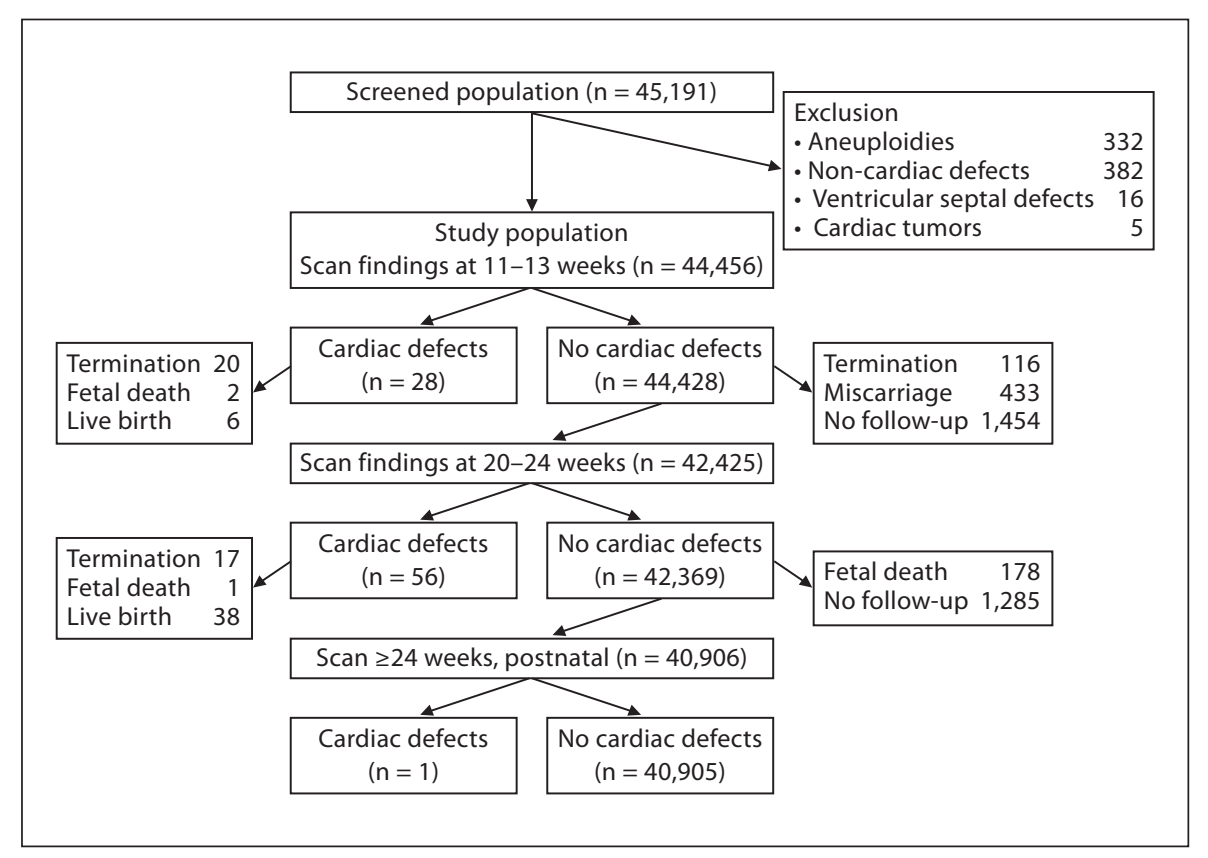

This study constitutes a retrospective analysis of data derived from a routine clinical examination and did not require ethics committee approval.

\section{Literature Search}

We searched MEDLINE and EMBASE from 1999 to September 2010 to identify first-trimester studies reporting on the relationship between ductus venosus flow and major fetal cardiac defects in euploid fetuses.

\section{Statistical Analysis}

The prevalence of reversed a-wave and NT above the 95 and 99th centiles in fetuses with and without major cardiac defects was calculated and comparisons were performed by $\chi^{2}$ test or Fisher's exact test. Logistic regression analysis was used to determine the significant contributors in the prediction of cardiac defects. The performance of screening was determined by receiver operating characteristic (ROC) curves and the performance of different methods of screening was compared using the areas under the ROC curves (AUC) [16].

The statistical software packages PASW statistics 18.0 (SPSS Inc., Chicago, Ill., USA) and Medcalc (Medcalc Software, Mariakerke, Belgium) were used for the data analyses.

\section{Results}

\section{Study Population}

During the study period, we carried out an ultrasound examination at 11-13 weeks in 45,191 singleton pregnancies with a live fetus and CRL of $45-84 \mathrm{~mm}$ (fig. 1). The median maternal age was 31 (range 14-51) years, the me- dian weight was 66 (range 35-167) kg, the racial origin of the women was Caucasian in $75.4 \%$, African in $16.1 \%$, South Asian in 4.1\%, East Asian in $1.9 \%$ and mixed in $2.5 \%$.

In $332(0.7 \%)$ and in $382(0.8 \%)$ of the 45,191 cases, there was prenatal or postnatal diagnosis of aneuploidy and non-cardiac abnormalities, respectively, and these cases were also excluded from further analyses. We also excluded 16 cases of prenatal or postnatal diagnosis of ventricular septal defect and 5 cases of cardiac tumors.

\section{Major Cardiac Defects}

In the 11-13 weeks' scan, we diagnosed major cardiac defects in 28 of the 44,456 cases. In 2,003 cases with no cardiac defects at the 11-13 weeks' scan, there was a miscarriage or termination of the pregnancy for psychosocial reasons or the patients were lost to follow-up. In the remaining 42,425 cases, an ultrasound scan was carried out at 20-23 weeks and major cardiac defects were diagnosed in a further 56 cases. In 1,463 of the 42,369 cases with no cardiac defects at the 20-23 weeks' scan, there was subsequent fetal death or the pregnancies were lost to follow up. In the 40,906 cases resulting in live births, neonatal examination demonstrated a major cardiac defect in one case and no cardiac defects in 40,905 babies. Therefore, in total, 85 cases with major cardiac defects were detected. 
Table 1. Diagnosis and outcome of cardiac abnormalities and their relation to fetal nuchal translucency (NT) thickness above the 95th centile and reversed a-wave in the ductus venosus at the 11-13 weeks' scan

\begin{tabular}{|c|c|c|c|c|c|c|c|c|c|}
\hline \multirow[t]{2}{*}{ Cardiac abnormalities } & \multirow[t]{2}{*}{ Total } & \multirow{2}{*}{$\begin{array}{l}\text { NT }>95 \text { th } \\
\text { centile, } \%\end{array}$} & \multirow{2}{*}{$\begin{array}{l}\text { DV reversed } \\
\text { a-wave, \% }\end{array}$} & \multicolumn{3}{|c|}{ Diagnosis, n } & \multicolumn{3}{|c|}{ Outcome } \\
\hline & & & & $\begin{array}{l}11-13 \\
\text { weeks }\end{array}$ & $\begin{array}{l}20-24 \\
\text { weeks }\end{array}$ & $\begin{array}{l}>24 \\
\text { weeks }\end{array}$ & TOP & $\begin{array}{l}\text { Misc/ } \\
\text { IUD }\end{array}$ & LB \\
\hline Coarctation of the aorta & 16 & $4(25.0)^{*}$ & $2(12.5)$ & 4 & 11 & 1 & 3 & 1 & 12 \\
\hline Tetralogy of Fallot (TOF) & 13 & $6(46.2)^{*}$ & $3(23.1)$ & 4 & 9 & - & 5 & - & 8 \\
\hline Hypoplastic left heart & 10 & $4(40.0)^{*}$ & $1(10)$ & 5 & 5 & - & 8 & - & 2 \\
\hline Ebstein's anomaly & 5 & $1(20.0)$ & $1(20.0)$ & - & 5 & - & 1 & - & 4 \\
\hline Transposition of the great arteries & 6 & $1(16.7)$ & $2(33.3)$ & 3 & 3 & - & 2 & 1 & 3 \\
\hline Pulmonary stenosis (PS) & 5 & $1(20.0)$ & $2(40.0)$ & - & 5 & - & - & - & 5 \\
\hline Pulmonary atresia (PA) & 3 & $2(66.7)^{*}$ & $2(66.7)$ & 1 & 2 & - & 3 & - & - \\
\hline Tricuspid atresia & 1 & 0 & 0 & - & 1 & - & 1 & - & - \\
\hline Left atrial isomerism & 1 & - & - & 1 & - & - & 1 & - & - \\
\hline Double inlet left ventricle & 2 & - & - & - & 2 & - & - & - & 2 \\
\hline AVSD, DORV and PA & 1 & - & - & - & 1 & - & 1 & - & - \\
\hline Total & 85 & $30(35.3 \%)^{*}$ & $24(28.2 \%)$ & 28 & 56 & 1 & 37 & 3 & 45 \\
\hline
\end{tabular}

TOP = Termination; Misc $=$ miscarriage $<24$ weeks; IUD = intrauterine death $\geq 24$ weeks; LB = live birth.

* Significance of the difference in proportion of cases with fetal NT $>95$ th centile in the study group compared to the screening population examined by $\chi^{2}$ test, $\mathrm{p}<0.05$.

The types of major cardiac defects and their relation to fetal nuchal translucency (NT) thickness above the 95th centile and reversed a-wave in the ductus venosus at the 11-13 weeks' scan are summarized in table 1.

The fetal NT was above the 95th and above the 99th centile in $30(35.3 \%)$ and $18(21.2 \%)$, respectively, of the 85 fetuses with major cardiac defects and in 1,956 (4.8\%) and 290 (0.7\%), respectively, of the 40,905 with no cardiac defects (table 2). Reversed a-wave in the ductus venosus was observed in $24(28.2 \%)$ of the fetuses with major cardiac defects and in 856 (2.1\%) of those with no cardiac defects. Reversed a-wave was found in 14 (46.7\%) of the 30 fetuses with cardiac defects and NT above the 95th centile, compared to $10(18.2 \%)$ of the 55 with NT at or below the 95th centile $(\mathrm{p}=0.005)$. Similarly, reversed a-wave was found in $80(4.1 \%)$ of the 1,956 fetuses with no cardiac defects and NT above the 95th centile, compared to 776 (2.0\%) of the 38,949 with NT at or below the 95th centile ( $<<$ $0.001)$.

The cardiac defects were grouped into the following groups: left heart disease (hypoplastic left heart syn- drome, coarctation of the aorta, aortic valve stenosis), right heart disease (pulmonary stenosis or atresia, tricuspid valve atresia, Ebstein's anomaly), conotruncal anomalies (transposition of the great arteries, tetralogy of Fallot, double outlet right ventricle), atrioventricular septal defect and other (double inlet left ventricle, tricuspid dysplasia, left atrial isomerism, complex atrioventricular septal defect). There were no significant differences between the five groups in the prevalence of NT above the 95 th centile $(\mathrm{p}=0.398)$ or reversed a-wave in the ductus venosus ( $p=0.063$; table 3 ). The prevalence of reversed a-wave was not significantly different for the different types of cardiac abnormalities either in the subgroup with normal NT $(\mathrm{p}=0.653)$ or in those with increased NT $(\mathrm{p}=0.113$; table 3$)$.

\section{Performance of Screening for Major Cardiac Defects}

The performance of different combinations of increased fetal NT and abnormal blood flow in the ductus venosus in screening for major cardiac defects is summarized in table 2. In these calculations it is assumed that all 
Table 2. Performance of screening for major cardiac defects by fetal nuchal translucency (NT), ductus venosus flow and combinations of these markers

\begin{tabular}{|c|c|c|c|c|}
\hline \multirow[t]{3}{*}{ Screening test by } & \multicolumn{4}{|c|}{ Major cardiac defect } \\
\hline & \multicolumn{2}{|c|}{ present $(n=85)$} & \multicolumn{2}{|c|}{ absent $(\mathrm{n}=40,905)$} \\
\hline & $\mathrm{n}(\%)$ & $95 \% \mathrm{CI}$ & $\mathrm{n}(\%)$ & $95 \% \mathrm{CI}$ \\
\hline NT above the 99th centile & $18(21.2)$ & $13.8-31.1$ & $290(0.7)$ & $0.6-0.8$ \\
\hline NT between the 95th and 99th centile & $12(14.1)$ & $8.1-23.2$ & $1,666(4.1)$ & $3.9-4.3$ \\
\hline NT above the 95th centile & $30(35.3)$ & $26.0-45.9$ & $1,956(4.8)$ & $4.6-5.0$ \\
\hline Reversed a-wave in ductus venosus & $24(28.2)$ & $19.7-38.6$ & $856(2.1)$ & $2.0-2.2$ \\
\hline Plus NT above the 99th centile & $33(38.8)$ & $29.2-49.5$ & $1,118(2.7)$ & $2.6-2.9$ \\
\hline Plus NT between the 95th and 99th centile & $31(36.5)$ & $27.0-47.7$ & $2,470(6.0)$ & $5.8-6.3$ \\
\hline Plus NT above the 95th centile & $40(47.1)$ & $36.8-57.6$ & $2,732(6.7)$ & $6.4-6.9$ \\
\hline
\end{tabular}

Table 3. Incidence of nuchal translucency thickness above the 95th centile and reversed a-wave in the ductus venosus for different categories of major cardiac defects

\begin{tabular}{lcrrrr}
\hline Major cardiac defects & Total & NT $>95$ th & \multicolumn{3}{l}{ Ductus venosus reversed a-wave } \\
\cline { 5 - 6 } & & & All & NT $\leq 95$ th & NT $>95$ th \\
\hline Left heart disease & 27 & $8(29.6)$ & $4(14.8)$ & $3 / 19(15.8)$ & $1 / 8(12.5)$ \\
Right heart disease & 14 & $4(28.6)$ & $5(35.7)$ & $2 / 10(20.0)$ & $3 / 4(75.0)$ \\
Conotruncal anomalies & 27 & $13(48.1)$ & $10(37.0)$ & $3 / 14(21.4)$ & $7 / 13(53.8)$ \\
Atrioventricular septal defect & 10 & $4(40.0)$ & $5(50.0)$ & $2 / 6(33.3)$ & $3 / 4(75.0)$ \\
Other & 7 & $1(14.3)$ & 0 & $0 / 6$ & $0 / 1$ \\
\hline Total & 85 & $30(35.3)$ & $24(28.2)$ & $10 / 55(18.2)$ & $14 / 30(46.7)$ \\
\hline
\end{tabular}

Comparisons by $\chi^{2}$ test. Figures in parentheses are percentages.

major cardiac defects can be detected antenatally by specialist fetal echocardiography.

The detection rate of major cardiac defects is essentially dependent on the availability of special fetal cardiac services. If all cases with fetal NT above the 95th centile and/or those with reversed a-wave are examined, 40 (47.1\%) of the 85 major cardiac defects would be detected but the false-positive rate would be $6.7 \%$ (2,732 of 40,905 with no cardiac defects). The lowest false-positive rate would be achieved by a policy of specialist fetal echocardiography reserved only for those with NT above the 99th centile $(0.7 \%)$, but the detection rate would be only $21.2 \%$. Echocardiography for cases with NT above the 99th centile and those with reversed a-wave in ductus venosus, irrespective of NT, would detect $38.8 \%$ of major cardiac defects at an overall false-positive rate of $2.7 \%$.
Logistic regression analysis showed that significant prediction of cardiac defects was provided by $\Delta \mathrm{NT}$ in $\mathrm{mm}$ (OR 2.6, 95\% CI 2.2-3.1, $\mathrm{p}<0.001)$ and reversed awave in the ductus venosus (OR 13.7, 95\% CI 8.2-22.8, $\mathrm{p}<0.001)$.

The patient-specific risk for major cardiac defects can be calculated from the formula: odds/(1 + odds), where odds $=\mathrm{e}^{\mathrm{Y}}$. The $\mathrm{Y}$ for the relation between cardiac defects and delta NT was derived by univariate logistic regression analysis $(\mathrm{Y}=-6.546+1.104 \times \Delta \mathrm{NT}$ in $\mathrm{mm})$. The $\mathrm{Y}$ for a combination of $\Delta \mathrm{NT}$ and reversed a-wave was derived by multivariate logistic regression $(\mathrm{Y}=-6.767+0.968 \times$ $\Delta \mathrm{NT}$ in $\mathrm{mm}+2.616$ if reversed a-wave in the ductus venosus and 0 if normal flow). The relation between the patient-specific risk for cardiac defect and fetal $\Delta \mathrm{NT}$ with and without reversed a-wave is illustrated in figure 2 . 


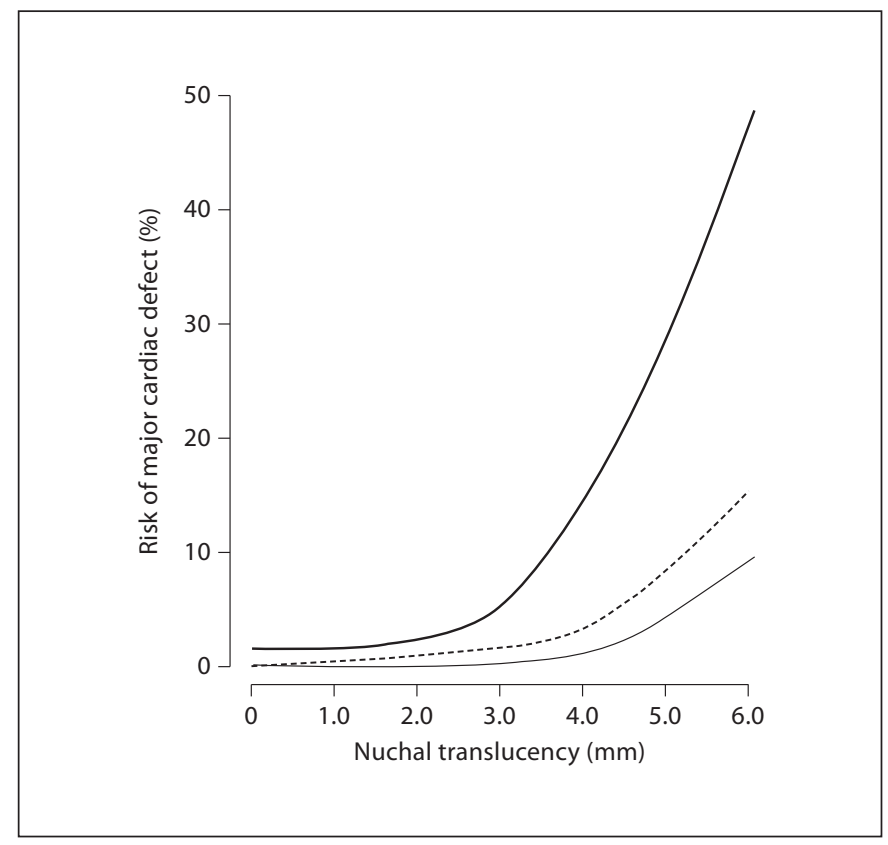

Fig. 2. Patient-specific risk for major cardiac defects according to fetal nuchal translucency thickness (dotted line) and in the presence (light solid line) or absence (thick solid line) of reversed awave in the fetal ductus venosus in a fetus with crown-rump length of $65 \mathrm{~mm}$.

The AUCs for the prediction of cardiac defects by NT alone was 0.700 (95\% CI, 0.635-0.764), and this was significantly improved by the addition of ductus venosus flow (AUC, 0.749, 95\% CI, 0.686-0.811, p<0.001) (fig. 3). For fixed false-positive rates of 1,3 and $5 \%$, the detection rates of major cardiac defects by NT alone were $25.9 \%$ (95\% CI, 17.7-36.2), 30.6\% (95\% CI, 21.8-41.1) and 35.3\% (95\% CI, 26.0-45.9), respectively, whereas by NT combined with ductus venosus flow the detection rates were $29.4 \%$ (95\% CI, 20.8-39.9), 40.0\% (95\% CI, 30.3-50.6) and $44.7 \%$ (95\% CI, 34.6-55.3).

\section{Literature Search}

The literature search identified eight studies providing data on the association between major cardiac defects and ductus venosus flow in euploid fetuses. In the total of 911 fetuses with increased NT, abnormal ductus venosus flow was observed in 40 of the 58 (69\%) with major cardiac defects and in 172 of the 853 (20.2\%) without cardiac defects (table 4).

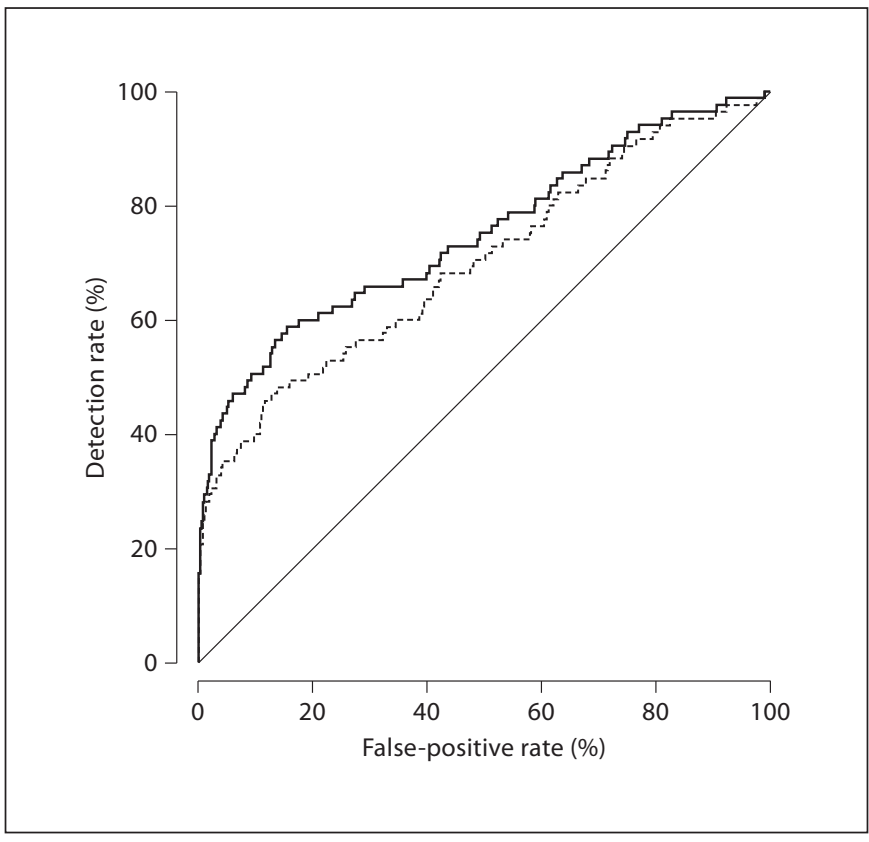

Fig. 3. Receiver-operator characteristics curves of nuchal translucency (dotted line) and nuchal translucency combined with ductus venosus flow (thich solid line) in the prediction of fetal major cardiac defects.

\section{Discussion}

The findings of this study demonstrate that in fetuses with major cardiac defects abnormal flow in the ductus venosus is observed not only in those with increased NT but also in those with normal NT. Consequently, the performance of early screening for cardiac defects achieved by measurement of fetal NT is improved by assessment of flow in the ductus venosus.

The overall prevalence of major cardiac defects in our population of euploid fetuses was 2 per 1,000. In all live births the diagnosis of cardiac defects was based on clinical examination in the neonatal period. It is therefore likely that in some defects, such as coarctation of the aorta and transposition of the great arteries, the diagnosis may have been missed. Another limitation of this study is the method of diagnosing or excluding a cardiac defect in cases of pregnancy termination or fetal death. We selected the pragmatic end-point of sonographically detectable defect by a pediatric cardiologist specialist in fetal echocardiography. Ideally, in these cases the antenatal findings should have been validated by postmortem examination. 
Table 4. Previous studies reporting on the relationship between ductus venosus waveforms and major cardiac defects in euploid fetuses with increased nuchal translucency thickness

\begin{tabular}{|c|c|c|c|c|c|}
\hline Author & Total & $\begin{array}{l}\text { NT } \\
\text { cut-off }\end{array}$ & $\begin{array}{l}\text { Major cardiac } \\
\text { defects }\end{array}$ & \multicolumn{2}{|c|}{ Abnormal ductus venosus flow } \\
\hline Murta et al., 2002 [20] & 16 & 95th centile & $1(6.3)$ & $0 / 15$ & $1 / 1(100)$ \\
\hline Haak et al., $2003[21]^{*}$ & 21 & 95th centile & $1(4.8)$ & $8 / 20(40.0)$ & $1 / 1(100)$ \\
\hline Favre et al., 2003 [22]* & 93 & 95th centile & $7(7.5)$ & $20 / 86(23.3)$ & $7 / 7(100)$ \\
\hline Timmerman et al., $2010[25]^{* *}$ & 309 & 95th centile & $24(7.8)$ & $77 / 285(27.0)$ & $12 / 24(50.0)$ \\
\hline Total & 911 & & $58(6.4)$ & $172 / 853(20.2)$ & $40 / 58(69.0)$ \\
\hline
\end{tabular}

\footnotetext{
* In these studies there were some cases of ventricular septal defects which were excluded from the current analysis. ${ }^{* *}$ Includes the
} data from Bilardo et al., 2001 [26]. Figures in parentheses are percentages.

The study confirmed that the prevalence of major cardiac defects increases with fetal NT thickness [17]. The prevalence was 58 per 1,000 in fetuses with NT above the 99th centile, 7 per 1,000 in those with NT between the 95th and 99th centile and 1 per 1,000 in those with NT at or below the 95th centile. The fetal NT was above the 95th and above the 99th centile in about 35 and 20\%, respectively, of the fetuses with major cardiac defects and in less than 5 and 1\%, respectively, of those with no cardiac defects. The offer of specialist fetal echocardiography to pregnancies with fetal NT above the 99th centile is now well accepted because the number of cases is small and the prevalence of major cardiac defects is high. The extent to which specialist fetal echocardiography should also be offered to pregnancies with NT between the 95th and 99th centiles, which constitute about $4 \%$ of the total population, depends on the availability of such services.

The prevalence of reversed a-wave in the ductus venosus increases with fetal NT in both the fetuses with a major cardiac defect and in those with no apparent defect. Reversed a-wave was observed in $2 \%$ of the normal fetuses with NT at or below the 95th centile and in $4 \%$ of those with NT above the 95th centile. The respective values for the fetuses with major cardiac defects were 18 and $47 \%$. In the combined data from studies in fetuses with increased NT, abnormal ductus venosus flow was reported in $20 \%$ of the normal fetuses and in $69 \%$ of those with major cardiac defects. These rates are substantially higher than in our screening study and suggest that the previous small series were examining many pregnancies with very high fetal NT. Our results in fetuses with major cardiac defects are similar to those of a previous screening study of 5,925 pregnancies where abnormal flow in the ductus venosus was observed in 4 of the 31 (12.9\%) with normal NT and in 6 of the 13 (46.1\%) with increased NT [11].

High NT and/or abnormal flow in the ductus venosus was not confined to specific types of cardiac defects. A previous smaller study also reported no particular type of cardiac defects in fetuses with abnormal ductus venosus flow and increased NT, but in fetuses with normal NT all defects were right-sided [11].

The underlying mechanism for the association between abnormal flow in the ductus venosus and cardiac defects is uncertain. Some of the cardiac defects that are not associated with heart failure during the second and third trimesters but with heart failure after birth have a reversed a-wave in the ductus venosus in the first trimester $[8,18,19]$. The fetal heart has a lower compliance than an adult heart, and this is more evident in the first trimester, where the predominance of the atrial contraction wave is greater than in later gestation. In addition, cardiac afterload is greater in the first trimester because of higher placental resistance. We could therefore speculate that in the first trimester, only a small impairment of the cardiac diastolic function might be enough for cardiac dysfunction to become evident as a reversed a-wave in the ductus venosus.

In this study, we developed an algorithm combining fetal NT with ductus venosus flow to estimate the patient- 
specific risk for major cardiac defects. The risk increases exponentially with NT and is further increased if the awave is reversed and decreased if flow in the ductus venosus is normal. For fixed false-positive rates of 1,3 and $5 \%$, the estimated detection rates of major cardiac defects in screening by fetal NT alone were 26,31 and $35 \%$, respectively, and these were increased by about $10 \%$ in screening by a combination of NT and ductus venosus flow. Ultimately, the detection of major cardiac defects will depend on the proportion of the population that can be offered specialist fetal echocardiography and our algorithm could be used to define the risk cut-off that selects the patients requiring referral for such an examination.
A more pragmatic approach would be to select patients on the basis of ductus venosus flow and a fetal NT cut-off. Ideally, all cases with fetal NT above the 95th centile and those with reversed a-wave should be offered fetal echocardiography, but in the absence of sufficient resources the examination could be reserved for those with abnormal Doppler and those with NT above the 99th centile.

\section{Acknowledgment}

This study was supported by a grant from The Fetal Medicine Foundation (UK charity number 1037116).

\section{References}

1 Office for National Statistics: Mortality Statistics, 2007. Childhood, infancy and perinatal. Series DH3, 40 .

2 Bull C: Current and potential impact of fetal diagnosis on prevalence and spectrum of serious congenital heart disease at term in the UK: British paediatric cardiac association. Lancet 1999;354:1242-1247.

3 Bricker L, Garcia J, Henderson J, Mugford M, Neilson J, Roberts T, Martin MA: Ultrasound screening in pregnancy: a systematic review of the clinical effectiveness, cost-effectiveness and women's views. Health Technol Assess 2000;4:i-vi, 1-193.

-4 Tegnander E, Williams W, Johansen OJ, Blaas HG, Eik-Nes SH: Prenatal detection of heart defects in a non-selected population of 30,149 fetuses - detection rates and outcome. Ultrasound Obstet Gynecol 2006;27:252-265.

$\checkmark 5$ Allan LD: Echocardiographic detection of congenital heart disease in the fetus: present and future. Br Heart J 1995;74:103-106.

6 Hyett J, Perdu M, Sharland G, Snijders R, Nicolaides KH: Using fetal nuchal translucency to screen for major congenital cardiac defects at 10-14 weeks of gestation: Population based cohort study. BMJ 1999;318:81-85.

7 Syngelaki A, Chelemen T, Dagklis T, Allan LD, Nicolaides KH: Challenges in the diagnosis of fetal non-chromosomal abnormalities at 11-13 weeks. Prenat Diagn 2010;in press.

-8 Matias A, Huggon I, Areias JC, Montenegro $\mathrm{N}$, Nicolaides KH: Cardiac defects in chromosomally normal fetuses with abnormal ductus venosus blood flow at 10-14 weeks. Ultrasound Obstet Gynecol 1999;14:307-310.

-9 Maiz N, Nicolaides KH: Ductus venosus in the first trimester: contribution to screening of chromosomal, cardiac defects and monochorionic twin complications. Fetal Diagn Ther 2010;28:65-71.

10 Maiz N, Valencia C, Emmanuel EE, Staboulidou I, Nicolaides KH: Screening for adverse pregnancy outcome by ductus venosus Doppler at $11-13^{+6}$ weeks of gestation. Obstet Gynecol 2008;112:598-605.
1 Martinez JM, Comas M, Borrell A, Bennasar M, Gomez O, Puerto B, Gratacos E: Abnormal first-trimester ductus venosus blood flow: a marker of cardiac defects in fetuses with normal karyotype and nuchal translucency. Ultrasound Obstet Gynecol 2010;35: 267-272.

12 Robinson HP, Fleming JE: A critical evaluation of sonar 'crown-rump length' measurements. Br J Obstet Gynaecol 1975;82:702710.

13 Snijders RJ, Noble P, Sebire N, Souka A, Nicolaides KH: UK multicentre project on assessment of risk of trisomy 21 by maternal age and fetal nuchal-translucency thickness at 10-14 weeks of gestation: fetal medicine foundation first trimester screening group. Lancet 1998;352:343-346.

14 Kagan KO, Wright D, Baker A, Sahota D, Nicolaides KH: Screening for trisomy 21 by maternal age, fetal nuchal translucency thickness, free beta-human chorionic gonadotropin and pregnancy-associated plasma protein-a. Ultrasound Obstet Gynecol 2008:31:618-624.

- 15 Maiz N, Kagan KO, Milovanovic Z, Celik E, Nicolaides KH: Learning curve for Doppler assessment of ductus venosus flow at $11^{+0}$ to $13^{+6}$ weeks' gestation. Ultrasound Obstet Gynecol 2008;31:503-506.

16 Zweig MH, Campbell G: Receiver-operating characteristic (ROC) plots: a fundamental evaluation tool in clinical medicine. Clin Chem 1993;39:561-577.

17 Atzei A, Gajewska K, Huggon IC, Allan L, Nicolaides KH: Relationship between nuchal translucency thickness and prevalence of major cardiac defects in fetuses with normal karyotype. Ultrasound Obstet Gynecol 2005;26:154-157.

18 Gembruch U, Meise C, Germer U, Berg C, Geipel A: Venous Doppler ultrasound in 146 fetuses with congenital heart disease. Ultrasound Obstet Gynecol 2003;22:345-350.
19 Hung JH, Fu CY, Lu JH, Hung CY: Ductus venosus blood flow resistance and congenital heart defects in the second trimester. J Clin Ultrasound 2008;36:72-78.

20 Murta CG, Moron AF, Avila MA, Weiner CP: Application of ductus venosus Doppler velocimetry for the detection of fetal aneuploidy in the first trimester of pregnancy. Fetal Diagn Ther 2002;17:308-314.

21 Haak MC, Twisk JW, Bartelings MM, Gittenberger-de Groot AC, van Vugt JM: Ductus venosus flow velocities in relation to the cardiac defects in first-trimester fetuses with enlarged nuchal translucency. Am J Obstet Gynecol 2003;188:727-733.

-22 Favre R, Cherif Y, Kohler M, Kohler A, Hunsinger MC, Bouffet N, Tanghe M, Cancellier M, Nisand I: The role of fetal nuchal translucency and ductus venosus doppler at 11-14 weeks of gestation in the detection of major congenital heart defects. Ultrasound Obstet Gynecol 2003;21:239-243

23 Toyama JM, Brizot ML, Liao AW, Lopes LM, Nomura RM, Saldanha FA, Zugaib M: Ductus venosus blood flow assessment at 11 to 14 weeks of gestation and fetal outcome. Ultrasound Obstet Gynecol 2004;23:341-345.

24 Maiz N, Plasencia W, Dagklis T, Faros E, Nicolaides K: Ductus venosus Doppler in fetuses with cardiac defects and increased nuchal translucency thickness. Ultrasound Obstet Gynecol 2008;31:256-260.

25 Timmerman E, Clur SA, Pajkrt E, Bilardo CM: First trimester measurement of the ductus venosus PIV and the prediction of congenital heart defects. Ultrasound Obstet Gynecol 2010 Jul 8. [Epub ahead of print].

26 Bilardo CM, Muller MA, Zikulnig L, Schipper M, Hecher K: Ductus venosus studies in fetuses at high risk for chromosomal or heart abnormalities: relationship with nuchal translucency measurement and fetal outcome. Ultrasound Obstet Gynecol 2001;17: 288-294. 